\title{
Dietary quality may enhance survival related to cognitive impairment in Taiwanese elderly
}

\author{
Rosalind Chia-Yu Chen', Yu-Hung Chang', Meei-Shyuan Lee, \\ Mark L. Wahlqvist ${ }^{1,2,3 *}$
}

Institute of Population Health Sciences, National Health Research Institutes, Taiwan, ROC; ${ }^{2}$ School of Public Health, National Defense Medical Center, Taiwan, ROC; ${ }^{3}$ Monash Asia Institute, Monash University, Melbourne, Australia

Abstract

Background: Impaired cognition increases mortality in the aged. It is unclear how dietary quality might affect this relationship.

Objective: To examine how dietary diversity and cognition might interact to determine survival.

Design: In a Nutrition and Health Survey in Taiwan (NAHSIT 1999-2000), 1,839 representative elderly were followed for mortality up to 10 years. The dietary quality measure was a dietary diversity score (DDS, range: 0-6) to present six food groups (dairy, meat, rice and grains, fruit, vegetable,fat and oil) derived from a 24-h dietary recall. Cognitive function was evaluated by the validated Short Portable Mental Status Questionnaire (SPMSQ).

Results: Those with cognitive impairment (SPMSQ $\geq 3$ errors) had 2.56 (95\% confidence intervals (CI), 1.99 3.28) times the all-cause-mortality risk of those with intact cognition. After control for potential confounders, the adjusted hazard ratio (HR) remained significant (1.46, 95\% CI: 1.06-2.02). Significant interactions for DDS and cognition were found $(p<0.001)$. Jointly, compared to normal-SPMSQ-highest DDS, the greatest HR is where impaired cognition is combined with the lowest DDS (HR 2.24, 95\% CI: 1.19-4.24). Increased DDS was associated with improvement in survival that is especially evident in those with 1-2 errors where the greatest HR reduction was found, and for fruit. Attributability for mortality amounted to $18 \%$ for impaired cognition and $33 \%$ for least diverse diet.

Conclusions: Dietary diversity may improve survival in relation to impaired cognitive function.

Keywords: dietary diversity; cognition; mortality; elderly; fruit

Received: 16 June 20II; Revised: 6 October 20II; Accepted: 6 October 201 I; Published: 30 October 20II

$\mathrm{C}$ ognitive impairment is prevalent and important in ageing. Among elderly, diet and other behaviours are associated with more than a $50 \%$ lowering of early death rate (1). Diet is a potential preventive approach against cognitive decline (2-4) as cognitive problems become an increasing issue in ageing populations. There are candidate food-based strategies that might minimise cognitive impairment $(4,5)$. The case for food patterns and foods as risk factors for cognitive impairment is supported by vegetarian and experimental studies with particular food items such as berries (6). There is little evidence for the macronutrient profile of the diet as a risk index for cognitive impairment, except that its glycaemic load will affect insulin resistance and glucose handling in the brain (7) and that n-3 fatty acids will contribute to neuronal plasticity and integrity, so favouring learning and cognition (8). Insofar as micronutrients and cognition are concerned, those for which the evidence seems strongest as protective are the vitamins B6 (9), folate (10) and B12 (11), with controversy about vitamin $\mathrm{E}$ (12) and iron (13), whereas zinc may be adverse (14). However, a spectrum of phytonutrients may provide neuroprotection with benefit for cognition and these include various polyphenols, notably anthocyanins. As yet, there is inconclusive evidence about dietary choline and neuroprotection, but because it is a constituent in brain phospholipids, it is likely to be important (15).

Regular physical activity improves cognition with advancing years and walking favours brain health as judged by PET scanning (16). Given that those with more varied diets are more likely to exercise $(2,3)$, dietary 
diversity may not only affect cognitive function in the aged but also improve survival (16-18). Diet may be most effective in elders who already have some degree of cognitive impairment (5). For example, eating a varied Mediterranean-type diet may help keep cognitive skills strong during old age (19), although for some quite complex food pattern, structural component and synergistic reasons (20).

We have found that a simple dietary diversity score (DDS) predicts mortality in elderly Taiwanese (18). We have studied how dietary diversity and cognition interact to determine survival in population-based elders.

\section{Methods}

\section{Study population}

The present study used data from the Elderly Nutrition and Health Survey in Taiwan (NAHSIT Elderly), a nationally representative sample of the free-living elderly aged 65 and over, conducted in 1999 and 2000. Details of design and sampling for this survey can be found elsewhere (21). The NAHSIT Elderly dataset was linked to the 1999-2008 National Death Registration data to determine survival status. All deaths that occurred between study entry and December 31, 2008 were included. Of 1,937 elderly persons who completed the household interview, 1,890 were successfully linked to the National Death Registry. Twenty-one, 28 and 2 participants had no Short Portable Mental Status Questionnaire (SPMSQ) data, no DDS data or an incorrect date of death, respectively. This left 1,839 eligible participants for analysis. All participants signed informed consent. The ethics committees of the National Health Research Institutes and of Academia Sinica approved the study protocol.

\section{Measurements}

The interview information was collected in households, face to face. Cognitive function was measured by the SPMSQ for assessing mental functioning of the elderly (22) and has been validated in Chinese in a Taiwanese population (23). This test included 10 questions dealing with orientation to time and place, personal history, longterm and short-term memory and calculations. They included: 'Where are you located now?'; 'What is your home address?'; 'What is the day of the week?'; 'What is the day, month, and year?'; 'How old are you?'; 'Who is the current president and who was the last president?'; and subtract from 20 by 3 for a total of four consecutive times. With total scores ranging from 0 to 10 , correct answers were coded 1 , whereas errors were coded 0 . In this study, participants were grouped into those who did not incur errors (SPMSQ $=10$, intact cognition), who incurred 1-2 errors: (SPMSQ $=8-9$, mild impairment) and who incurred three or more errors (SPMSQ $=0-7$, moderate to severe impairment). In this study, missing values and incomplete SPMSQ data were assigned an SPMSQ $=0$.

Dietary quality was measured by the DDS. From a 24hour recall, a DDS (ranged 1-6) was derived, a modification of the NHANES method (24). According to the Taiwanese Food Guides (25), half a serving per day for one of the six food groups including 'dairy', 'meat', 'grain', 'fruit', 'vegetable' and 'fat and oil' was the minimal intake required for a DDS score of 1 . The 'meat group' comprised protein rich foods, i.e. eggs, fish and shellfish, soybean products and meats. The higher scores indicate better nutrient intakes (18).

\section{Statistical analysis}

All data were weighted to represent the elderly population in Taiwan during 1999-2000. Chi-square tests were used for categorical variables across cognitive status groups. Cox's proportional hazards models were used to evaluate the effect of cognitive status on mortality from 1999 to 2008 with relevant covariates adjustment, including gender, age, education, ethnicity, substance abuse (alcohol drinking, smoking, betel nut chewing), exercise, region of abode, and financial status, number of comorbidities, energy intake and DDS. The models were further adjusted for marital status, living alone, food preparation, and physical function to evaluate the health independence of the elderly might affect the relationship between cognitive status and survival. All analyses were performed using SAS statistical software (version 9.1.3), and SUDAAN (version 10.0) was used to adjust for the design effect of sampling. Population attributable risk (PAR) was assessed for mortality attributed to cognitive impairment as opposed to normal mental state and also to dietary diversity.

\section{Results}

A total of 671 participants died in the 10 years follow-up from 1999 to 2008. Table 1 presents study variables and their distributions across four SPMSQ statuses. After weighting for representativeness of the participants, more than half $(56 \%)$ of the elderly had 0 errors, followed by $1-$ 2 errors $(27 \%)$, and 3 or more errors $(17 \%)$. The majority of the study population were aged younger than 75 years, males, married and also lived with their spouse or children, prepared their own food, had dietary quality scores greater than 3 and less than 6, were financially sufficient, non-alcohol drinkers, non-smokers and involved in frequent exercise. More than one-third could prepare food on their own.

Severe cognitive impairment was associated with older elders, female gender, no education, being indigenous, difficult finances, less exercise, low physical function, being never married, achieving less food variety (DDS $\leq 3$ ), dining with children and relatives, 
Table 1. Distributions of demographics and study variables by cognitive status in NAHSIT 1999-2000 participants

\begin{tabular}{|c|c|c|c|c|c|}
\hline \multirow[b]{2}{*}{ Descriptor } & \multirow[b]{2}{*}{$n^{\mathrm{b}}$} & \multicolumn{3}{|c|}{ SPMSQ (\%) ${ }^{\mathrm{a}}$} & \multirow[b]{2}{*}{$p^{c}$} \\
\hline & & 0 errors & $\mathrm{I}-2$ errors & $\geq 3$ errors & \\
\hline Total & $\mathrm{I}, 839$ & 56.2 & 26.5 & 17.4 & \\
\hline Gender & & & & & $<0.001$ \\
\hline Male & 925 & 69.9 & 21.3 & 8.8 & \\
\hline Female & 914 & 40.4 & 32.5 & 27.1 & \\
\hline Age at baseline, years & & & & & $<0.001$ \\
\hline $65-69$ & 609 & 66.6 & 24.3 & 9.2 & \\
\hline $70-74$ & 636 & 64.6 & 23.0 & 12.4 & \\
\hline $75-97$ & 594 & 40.8 & 31.2 & 28.0 & \\
\hline Education & & & & & $<0.001$ \\
\hline Illiterate & 632 & 31.9 & 33.8 & 34.3 & \\
\hline Elementary school and below & 822 & 63.9 & 26.0 & 10.1 & \\
\hline High school & 317 & 79.9 & 16.6 & 3.5 & \\
\hline College and above & 62 & 87.1 & 10.4 & 2.6 & \\
\hline Ethnicity & & & & & $<0.001$ \\
\hline Non-indigenous & $\mathrm{I}, 654$ & 56.8 & 26.1 & 17.1 & \\
\hline Indigenous & 183 & 19.9 & 47.7 & 32.4 & \\
\hline Perceived financial status & & & & & $<0.01$ \\
\hline Enough or just enough & $\mathrm{I}, 246$ & 60.2 & 26.1 & 13.8 & \\
\hline Some difficulty & 436 & 47.0 & 29.4 & 23.6 & \\
\hline Very difficult & 96 & 31.2 & 29.2 & 39.6 & \\
\hline Alcohol drinker & & & & & $<0.001$ \\
\hline No & $\mathrm{I}, 350$ & 52.2 & 27.3 & 20.5 & \\
\hline Former & 122 & 63.6 & 26.0 & 10.4 & \\
\hline Current & 363 & 69.6 & 24.0 & 6.4 & \\
\hline Smoker & & & & & $<0.001$ \\
\hline Never & 1,198 & 49.7 & 28.5 & 21.8 & \\
\hline Former & 231 & 68.3 & 20.5 & 11.3 & \\
\hline Current & 401 & 65.7 & 25.2 & 9.1 & \\
\hline Betel nut chewing & & & & & 0.6 \\
\hline No & 1,688 & 56.6 & 26.2 & 17.2 & \\
\hline Former & 53 & 51.6 & 30.0 & 18.6 & \\
\hline Current & 94 & 44.2 & 32.6 & 23.2 & \\
\hline Exercise frequently & & & & & $<0.001$ \\
\hline No & 892 & 46.8 & 28.2 & 25.0 & \\
\hline Yes & 941 & 63.6 & 25.1 & 11.3 & \\
\hline Marital status & & & & & $<0.001$ \\
\hline Never & 43 & 55.8 & 28.1 & 16.1 & \\
\hline Yes and live together & 1,213 & 63.6 & 23.8 & 12.6 & \\
\hline Divorced or widowed & 581 & 40.8 & 31.6 & 27.6 & \\
\hline Dietary Diversity Score, DDS & & & & & $<0.001$ \\
\hline$\leq 3$ & 341 & 48.9 & 25.0 & 26.1 & \\
\hline 4 & 610 & 47.5 & 30.5 & 22.0 & \\
\hline 5 & 606 & 61.1 & 26.5 & 12.4 & \\
\hline 6 & 282 & 68.4 & 20.8 & 10.8 & \\
\hline
\end{tabular}




\begin{tabular}{|c|c|c|c|c|c|}
\hline \multirow[b]{2}{*}{ Descriptor } & \multirow[b]{2}{*}{$n^{\mathrm{b}}$} & \multicolumn{3}{|c|}{ SPMSQ (\%) ${ }^{\mathrm{a}}$} & \multirow[b]{2}{*}{$p^{c}$} \\
\hline & & 0 errors & $\mathrm{I}-2$ errors & $\geq 3$ errors & \\
\hline Dinner companions & & & & & $<0.001$ \\
\hline Self & 312 & 49.9 & 29.8 & 20.3 & \\
\hline Spouse & 707 & 62.7 & 25.6 & 11.7 & \\
\hline Children and relatives & 806 & 53.1 & 26.0 & 20.9 & \\
\hline Friends or neighbours & 10 & 62.9 & 24.2 & 12.9 & \\
\hline Food preparation & & & & & $<0.001$ \\
\hline Never & 111 & 40.7 & 25.7 & 33.5 & \\
\hline Self & 741 & 60.8 & 26.4 & 12.8 & \\
\hline Spouse & 459 & 68.8 & 25.1 & 6.2 & \\
\hline Children or relatives & 494 & 43.5 & 28.4 & 28.1 & \\
\hline Friends or neighbours & 9 & 35.6 & 39.6 & 24.8 & \\
\hline House maid & 10 & 44.0 & 8.9 & 47.1 & \\
\hline Number of co-morbidities & & & & & 0.1 \\
\hline 0 & 342 & 60.7 & 25.8 & 13.5 & \\
\hline $\mathrm{I}-2$ & 832 & 56.6 & 26.3 & I7.I & \\
\hline $3-5$ & 553 & 52.1 & 28.9 & 19.0 & \\
\hline$\geq 6$ & 109 & 58.1 & 18.7 & 23.2 & \\
\hline Physical functioning & & & & & $<0.001$ \\
\hline$<45$ & 471 & 33.2 & 29.4 & 37.4 & \\
\hline $45-53.9$ & 578 & 53.4 & 33.8 & 12.8 & \\
\hline $54-57.9$ & 503 & 68.9 & 22.4 & 8.7 & \\
\hline$\geq 58$ & 268 & 79.9 & 15.3 & 4.8 & \\
\hline Region & & & & & $<0.001$ \\
\hline Hakka & 144 & 68.9 & 22.1 & 9.0 & \\
\hline Mountain area & 138 & 26.3 & 42.6 & 31.1 & \\
\hline Eastern area & 133 & 29.7 & 38.9 & 31.3 & \\
\hline PengHu Island & 147 & 40.6 & 26.4 & 33.0 & \\
\hline Northern I & 142 & 64.5 & 18.0 & 17.5 & \\
\hline Northern II & $14 \mid$ & 63.9 & 21.8 & 14.3 & \\
\hline Northern III & $|4|$ & 49.1 & 33.1 & 17.8 & \\
\hline Central I & 133 & 50.5 & 33.5 & 16.0 & \\
\hline Central II & 138 & 48.1 & 29.7 & 22.2 & \\
\hline Central III & 146 & 41.2 & 31.2 & 27.6 & \\
\hline Southern I & 142 & 55.0 & 33.3 & 11.7 & \\
\hline Southern II & 146 & 69.8 & 15.7 & 14.4 & \\
\hline Southern III & 148 & 51.8 & 30.4 & 17.9 & \\
\hline Duration of observation (median, years) & 1,839 & 8.8 & 8.9 & 7.5 & \\
\hline
\end{tabular}

a\% are weighted by SUDAAN to reflect their representation in the population.

${ }^{\mathrm{b}}$ Total sample size is 1,839; cases with missing values were not included for the relevant variable.

${ }^{\mathrm{c} C h i-s q u a r e}$ test.

NAHSIT, the Nutrition and Health Survey in Taiwan.

never preparing food, with most co-morbidity and living in mountainous and eastern areas, where the indigenous population is relatively greater (Table 1). Each of these variables was considered as a potential confounder in the following multi-variable analyses.
Notably, there were more who had severely impaired cognitive function among the deceased $(27.4 \%)$ and more who had intact cognition among survivors $(62.2 \%)$, which is indicative of an association between cognitive status and later mortality. 
Table 2 shows the models that predict the survivorship of the participants. Without any adjustment, it shows that mortality risk for 1-2 errors had a hazard ratio (HR) 1.34 (95\% confidence intervals (CI), 1.01-1.79), and for $\geq 3$ errors an HR 2.56 (95\% CI, 1.99-3.28) that demonstrated higher mortality risk as cognition became impaired $(p<$ 0.001 for all HRs). After adjustment for DDS in Model 1, HR was reduced for both $1-2$ errors and $\geq 3$ errors (HR 1.31, 95\% CI, 0.99-1.73; HR 2.33, 95\% CI, 1.87-2.92). Model 2, which was adjusted for a set of essential covariates, revealed that people who had impaired cognition were still at a higher risk of death than those who were normal. The highest risk of death was in the ' $\geq 3$ errors' category (HR 2.07, 95\% CI, 1.53-2.80). When controlling for marital status, living alone and food preparation to take into account family resources and supports and physical function, the HR for cognition and mortality was less apparent (HR 1.46, 95\% CI, 1.06-2.02) compared to that with intact function. The highest DDS (6) demonstrated improve survival in cognitive impairment compared with the lowest DDS $(\leq 3)$ (HR 0.57, 95\% CI, $0.40-0.81, p<0.01$ ) (data not shown).

In Model 5, which only includes participants without known dementia, DDS continues to be a predictor of survival in relation to cognitive impairment, even with these elders with relatively better mental health (HR 0.62; 95\% CI, 0.42-0.90, $p<0.05$ ) (data not shown).

Table 2. The relationships between cognition and risk of death in NAHSIT elderly

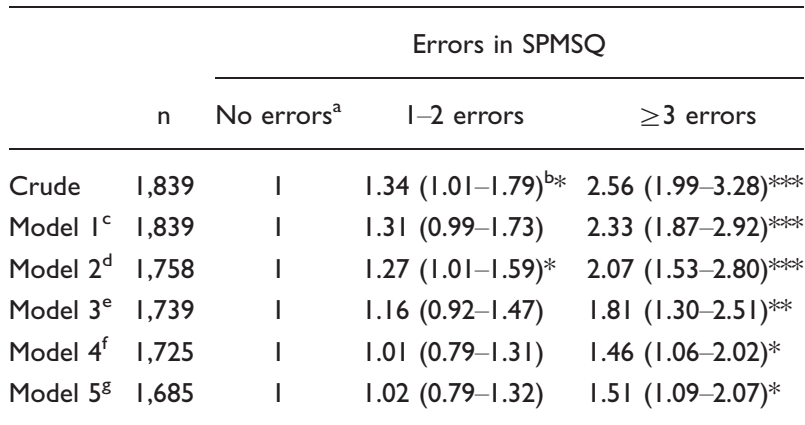

Significance is shown by $p<0.1$; ${ }^{*} p<0.05$; ${ }^{* *} p<0.01$; ${ }^{* * *} p<0.001$.

a'No errors' as reference group.

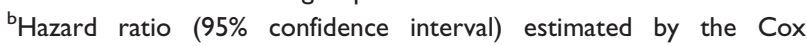
proportional hazards model.

'Model I: Adjusted for dietary diversity score (DDS).

Model 2: Adjusted by model I plus gender, age, education, ethnicity, alcohol drinking, smoking, betel nut chewing, exercise, region, financial status, number of co-morbidities and energy intake.

e Model 3: Adjusted by model 2 covariates plus marital status, living alone, food preparation (family resources and social supports) and DDS. ${ }^{\mathrm{f}}$ Model 4: Adjusted by model 3 covariates plus physical functioning and DDS.

${ }^{g}$ Model 5: Model 4 for a sub-sample which excluded those who had dementia.
Jointly, there is a significant interaction for DDS and cognitive function $(p<0.001)$ on risk of death (Fig. 1). There are relationships of dietary diversity to survival for each of the three levels cognition and because the first two levels ( 0 errors and 1-2 errors) were significant, any bias for the most severe cognitive impairment category due to erroneous responses is unlikely. The highest risk for death was where there were three or more errors and where it occurred together with the lowest DDS with reference to those with 0 errors and the highest DDS and after adjustment for co-variates (HR 2.24, 95\% CI: 1.19 $4.24, p<0.05)$. The increased DDS from the lowest to any of the higher categories was associated with improvement in survival that is especially evident in those with $1-$ 2 errors, where the greatest risk reduction of $59 \%$ was found. After stratification by cognitive status, the individual effects remained the same, which is to say that the risk of death decreases with increasing DDS.

The PAR for mortality attributed to cognitive impairment as opposed to normal mental state was $18 \%$ and to least diverse diet as opposed to most diverse diet was $33 \%$.

\section{Discussion}

\section{Attributability for mortality}

We found that cognition function predicts mortality among elderly Taiwanese and their survival may be improved by a diverse diet; diet accounted for about twice the PAR of cognition. When we explored whether dietary diversity could improve long-term survival in cognitively impaired elders, we found that the effect remained when relevant confounders were considered. Family or social support improves the cognitive functiondietary quality link in elderly survival as well (26).

\section{Cognition}

Older women who exercise less and are less-educated are more likely to have cognitive impairment (Table 1). Our previous findings which show that shopping activity is likely to benefit survival are consistent with the present findings because both physical and/or cognitive function might benefit from it (27).

Because mortality, DDS and cognitive function are highly associated with ageing, we have stratified our analyses by cognitive status, to understand to what extent SPMSQ may affect our findings. It remained the case that those with the lowest DDS had the greatest mortality at every level of cognitive function (data not shown).

Those who exercised less had 1.39 times higher risk of mortality than frequent exercisers $(p<0.01$, data not shown). When physical function was considered in the model, mortality risk from cognitive impairment was lowered, from 1.81 to 1.46 . This is consistent with other observations which indicate that exercise and 


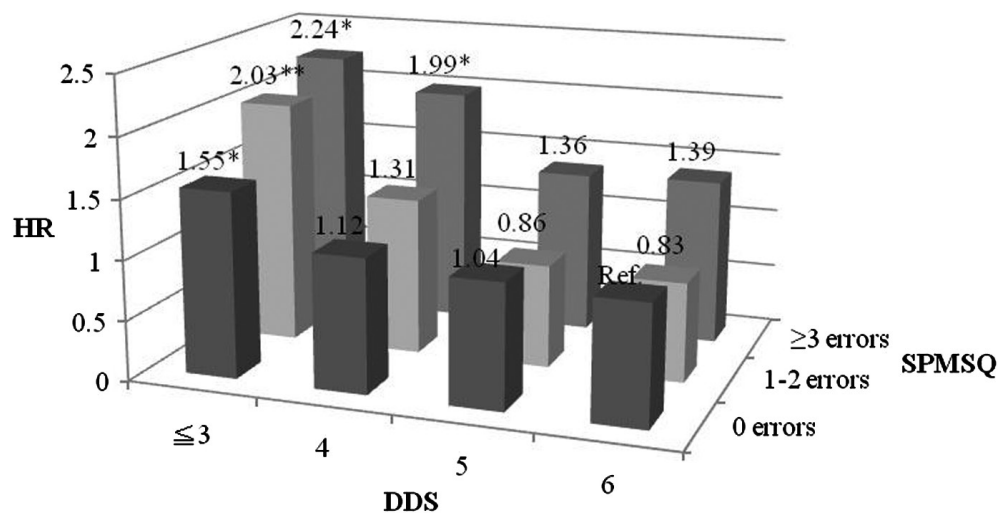

Fig. 1. Joint hazard ratios (HRs) for all cause mortality in elder Taiwanese after an 10-year follow-up in accordance with cognitive function and in relation to dietary diversity score (DDS). The model has been adjusted for gender, age, education, ethnicity, alcohol drinking, smoking, betel nut chewing, exercise, physical function, region, financial status, marital status, living alone, food preparation, number of co-morbidities and energy intake. Significance is shown by $* p<0 \cdot 05, * * p<0 \cdot 01$. There is significant interaction between DDS and cognition $(p<0.001)$.

physical function help cognition and benefit survival (16).

\section{Modifiability of risk for cognitive function and diet}

Cognitive function is an important predictor of mortality in the elderly $(28,29)$ and may be modifiable such as physical function (27), in contrast to non-modifiable predictors of death such as age and gender.

Dietary quality, of which dietary diversity by DDS is a measure, is also a predictor of mortality (18) and may serve as an intervention to improve survival through cognition. There is evidence too that the overall diet characterised by essential nutrient density is associated with better cognitive function in the elderly (2). But this might not be just a matter of food component compositions, because, for example, living and eating alone decrease consumption of fruits and vegetables in the elderly, especially in men (30). Family and social support are important factors in terms of ensuring a healthy diet and what effects this might have on mortality in those with cognitive impairment.

The cognition-dietary diversity association and mechanisms Of the six food groups that comprise the DDS, fruit is the most differentiated among the three cognitive groups, then dairy and vegetables. Fifty-nine percent of elderly with intact cognition consumed at least one defined fruit portion that was significantly higher than for those with 1-2 errors (45\%) and $\geq 3$ errors (38\%) (Fig. 2 \& See Supplementary Table).

For those with mild cognitive impairment (1-2 errors), the effect of DDS on survival was the greatest with a $59 \%$ reduction in the HR (from 2.03 to 0.83 ) (Fig. 1). The largest $\mathrm{HR}$ reductions took place from $\mathrm{DDS} \leq 3$ to 4 $(35 \%)$ and from 4 to $5(34 \%)$. With this level of impairment, we examined the differences of food intakes from $\mathrm{DDS} \leq 3$ to 5 . A $60 \%$ difference is seen in oil/fat intake because $22 \%$ of the population achieved one unit per day at DDS $\leq 3$, whereas $82 \%$ achieved this at DDS = 4; the difference for fruit was $51 \%$ and that for dairy was $27 \%$ between DDS 4 and 5. (See Supplementary Fig. $1-1)$. For those with $\geq 3$ errors, a $54 \%$ increase in oil/fat intake was observed when DDS increased from $\leq 3$ to 4 and there were 47 and $39 \%$ increases in fruit and dairy intakes, respectively, when DDS went from 4 to 5 (See Supplementary Fig. 1-2). For those with no error, although fruit and dairy intake also increased 48 and $23 \%$, respectively, when DDS increased from 4 to 5 , there was a limited mortality reduction (Fig. 1).

We can deduce that DDS improvements from 3 to 5 may enable an optimal reduction in death risk for cognitively impaired elders in later life. In addition, it appears that fruit and dairy, along with fat intake, may leverage a reduction in pre-mature death attributable to cognitive impairment. These results are consistent with previous studies of food intake and cognition $(4,16)$. Thus, additional fruit especially, but also dairy and vegetables, in the cognitively impaired may provide an acceptable food choice strategy to gain health benefit. They have clinical nutritional practice relevance and can inform public health policy decisions for preventive nutrition with the growing problem of dementia.

Our study draws attention to the relatively greater socio-economic disadvantages of those elderly who are cognitively impaired (Table 1). Insofar, as these disadvantages relate to literacy, isolation, physical function and food preparation, the resource implications of our findings will be affected.

\section{Limitations}

One limitation is that all measurements were collected at baseline and we cannot assess the effect of changes in diet 


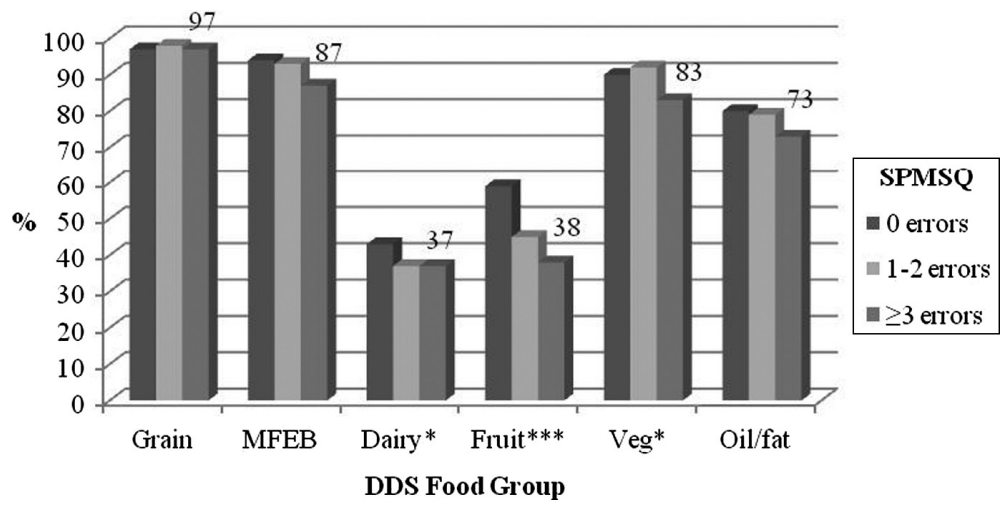

Fig. 2. Percentage of population that achieves an individual food group score of one per day by SPMSQ status. Statistical tests were done by the chi-square tests. ${ }^{*} p<0.05$ and ${ }^{* * *} p<0.001$. DDS, dietary diversity score; MFEB, meat/fish/egg/beans.

and cognition status or imply cause and effect among the co-variates. In addition, the interpretation of the time frame over which the diet we have assessed has actually been operational is uncertain. We used 24-hour dietary recall to measure diet, and this may or may not have reflected past or future diet. We presume that diet was still operational in terms of cognition at the time of study but its effect may have been imprinted earlier or for later, for example, through epigenetic mechanisms. In addition, in this study we have used a different definition of cognitive impairment to Pfeiffer (22) to demonstrate a gradient related to DDS and mortality.

Again, our conclusions may be limited by an inadequate account of confounders. We have captured substance abuse from tobacco, alcohol and betel nut usage, but we have not been able to consider a subject's medication usage that might adversely or favourably affect cognition. A number of prescribed medications can affect well-being and with it cognition. On the other hand, more recent evidence shows that effective management of diabetes with metformin and sulfonylureas can ameliorate the decline in cognitive function seen with diabetes, now increasingly prevalent amongst the aged (7).

\section{Conclusions}

Both cognition and dietary diversity account for some of the survival risk in elderly Taiwanese.

\section{What is already known}

Both Cognition and dietary diversity predict mortality.

\section{What this study adds}

1. Greater dietary diversity predicts increased survival in those elderly with cognitive impairment.

2. Of the food groups that constitute the DDS used, especially fruit but also dairy and vegetable categories play a role in cognitive function of the elderly.
3. When account is taken of family resources, social supports and physical function, important in their own right, the diet-cognition-survival phenomenon remains unchanged.

\section{Acknowledgements}

This study was sponsored by the National Health Research Institutes and the Department of Health (DOH), Taiwan (DOH098-TD-F-113-098029).

\section{Conflict of interest and funding}

The authors have not received any funding or benefits from industry or elsewhere to conduct this study.

\section{References}

1. Knoops KT, de Groot LC, Kromhout D, Perrin AE, MoreirasVarela O, Menotti A, et al. Mediterranean Ddet, lifestyle factors, and 10-year mortality in elderly european men and women: The HALE Project. JAMA 2004; 292: 1433-9.

2. Ortega RM, Requejo AM, Andres P, Lo'pez-Sobaler AM, Quintas ME, Redondo MR, et al. Dietary intake and cognitive function in a group of elderly people. Am J Clin Nutr 1997; 66: 803-9.

3. Wengreen HJ, Neilson C, Munger R, Corcoran C. Diet quality is associated with better cognitive test performance among aging men and women. J Nutr 2009; 139: 1944-9.

4. Nurk E, Refsum H, Drevon CA, Smith AD, Tell GS, Nygaard HA, et al. Cognitive performance among the elderly in relation to the intake of plant foods. The Hordaland Health Study. Br J Nutr 2010; 104: 1190-201.

5. Feart C, Samieri C, Barberger-Gateau P. Mediterranean diet and cognitive function in older adults. Curr Opin Clin Nutr Metab 2010; 13: 14-8.

6. Joseph JA, Shukitt-Hale B, Denisova NA, Bielinski D, Martin A, McEwen JJ, et al. Reversals of age-Rrelated declines in neuronal signal transduction, cognitive, and motor behavioral deficits with blueberry, spinach, or strawberry dietary supplementation. J Neurosci 1999; 19: 8114-9.

7. Hsu CC, Wahlqvist ML, Lee MS, Tsai HN. Incidence of dementia is increased in type 2 diabetes and reduced by the use of sulfonylureas and metformin. J Alzheimers Dis 2011; 24: 485-93. 
8. Sinclair AJ, Begg D, Mathai M, Weisinger RS. Omega 3 fatty acids and the brain: review of studies in depression. Asia Pac $\mathrm{J}$ Clin Nutr 2007; 16: 391-7.

9. Murakami K, Miyake Y, Sasaki S, Tanaka K, Fukushima W, Kiyohara C, et al. Dietary intake of folate, vitamin B6, vitamin B12 and riboflavin and risk of Parkinson's disease: a casecontrol study in Japan. Br J Nutr 2010; 104: 757-64.

10. Lee LK, Shahar S, Rajab N. Serum folate concentration, cognitive impairment, and DNA damage among elderly individuals in Malaysia. Nutr Res 2009; 29: 327-34.

11. Kivipelto M, Annerbo S, Hultdin J, Backman L, Viitanen M, Fratiglioni L, et al. Homocysteine and holo-transcobalamin and the risk of dementia and Alzheimers disease: a prospective study. Eur Neurol 2009; 16: 808-13.

12. Devore EE, Grodstein F, van Rooij FJA, Hofman A, Stampfer MJ, Witteman JCM, et al. Dietary antioxidants and long-term risk of dementia. Arch Neurol 2010; 67: 819-25.

13. Falkingham M, Abdelhamid A, Curtis P, Fairweather-Tait S, Dye L, Hooper L. The effects of oral iron supplementation on cognition in older children and adults: a systematic review and meta-analysis. Nutr J 2010; 9: 1-16. doi:10.1186/1475-2891-9-4

14. Cherny RA, Atwood CS, Xilinas ME, Gray DN, Jones WD, McLean CA, et al. Treatment with a copper-zinc chelator markedly and rapidly inhibits beta-amyloid accumulation in Alzheimer's disease transgenic mice. Neuron 2001; 30: 665-76.

15. Zeisel SH. The fetal origins of memory: the role of dietary choline in optimal brain development. J Pediatr 2006; 149: 1316.

16. Erickson KI, Becker JT, Raji CA, Gach HM, Lopez OL, Rosano C, et al. Physical activity predicts gray matter volume in late adulthood: the Cardiovascular Health Study. Neurology 2010; 75: 1415-22.

17. Wahlqvist ML, Darmadi-Blackberry I, Kouris-Blazos A, Jolley D, Steen B, Lukito W, et al. Does diet matter for survival in long-lived cultures? Asia Pac J Clin Nutr 2005; 14: 2-6.

18. Lee MS, Huang YC, Su HH, Lee MZ, Wahlqvist ML. A simple food quality index predicts mortality in elderly Taiwanese. J. Nutr. Health Aging. doi: 10.1007/s12603-011-0081-x. (in press).

19. Knopman DS. Mediterranean diet and late-life cognitive impairment: a taste of benefit. JAMA 2009; 302: 686-7.
20. Trichopoulou A, Bamia C, Trichopoulos D. Anatomy of health effects of Mediterranean diet: Greek EPIC prospective cohort study. BMJ (Clinical research ed.) 2009; 338: b 1-8. doi:10.1136/ bmj.b2337.

21. Pan WH, Hung YT, Shaw SS, Lin W, Lee SD, Chiu CF, et al. Elderly nutrition and health survey in Taiwan (1999-2000): research design, methodology and content. Asia Pac J Clin Nutr 2005; 14: 203-10.

22. Pfeiffer E. A short portable mental status questionnaire for the assessment of organic brain deficit in elderly patients. J Am Geriatr Soc 1975; 23: 433-41.

23. Hsiao SH, Chiu HC, Liu HW. A replication of multidimensionality of activities of daily living (ADL): on the elderly in Southern Taiwan, Kaohsiung. J Med Sci 1994; 10: 449-57.

24. Kant AK, Schatzkin A, Harris TB, Ziegler RG, Block G. Dietary diversity and subsequent mortality in the First National Health and nutrition Examination Survey Epidemiologic Follow-up Study. Am J Clin Nutr 1993; 57: 434-40.

25. DOH. Food guides (Balance diet recommendations for adults). Taipei, Taiwan: Department of Health; 1995

26. Yeh SC, Liu YY. Influence of social support on cognitive function in the elderly. BMC Health Serv Res 2003; 3: 1-9.

27. Chang YH, Chen RCY, Wahlqvist ML, Lee MS. Frequent shopping by men and women increases survival in the older Taiwanese population. J Epidemiol Commun H. doi:10.1136/ jech.2010.126698 (in press).

28. Duff K, Mold J, Gidron Y. Cognitive functioning predicts survival in the elderly. J Clin Exp Neuropsychol 2009; 31: 90-5.

29. Xavier AJ, d'Orsi E, Sigulem D, Ramos LR. Time orientation and executive functions in the prediction of mortality in the elderly: epidoso study. Rev Saúde Pública 2010; 44: 148-58.

30. Hughes G, Bennett KM, Hetherington MM. Old and alone: barriers to healthy eating in older men living on their own. Appetite 2004; 43: 269-76.

*Mark L. Wahlqvist

Institute of Population Health Sciences

National Health Research Institutes

Taiwan 35053

Email: profmlw@nhri.org.tw 
Supplementary Table. Percentage of population which achieves an individual food group score of one per day by SPMSQ status. Statistical tests were done by the chi-square tests. ${ }^{*} p<0.05$ and ${ }^{* * *} p<0.001$. DDS, dietary diversity score; MFEB, meat/fish/egg/beans.

\begin{tabular}{lcccccc}
\hline & Grain & MFEB & Dairy* & Fruit*** & Veg* & Oil/fat \\
\hline 0 errors & 0.97 & 0.94 & 0.43 & 0.59 & 0.9 & 0.8 \\
I-2 errors & 0.98 & 0.93 & 0.37 & 0.45 & 0.92 & 0.79 \\
$\geq 3$ errors & 0.97 & 0.87 & 0.37 & 0.38 & 0.83 & 0.73 \\
\hline
\end{tabular}

(a)

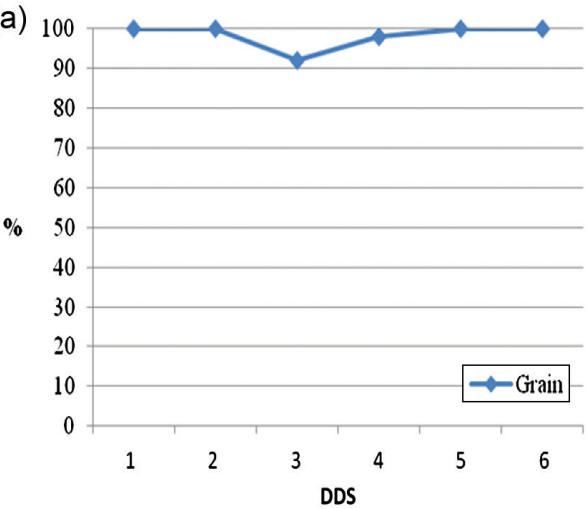

(c)

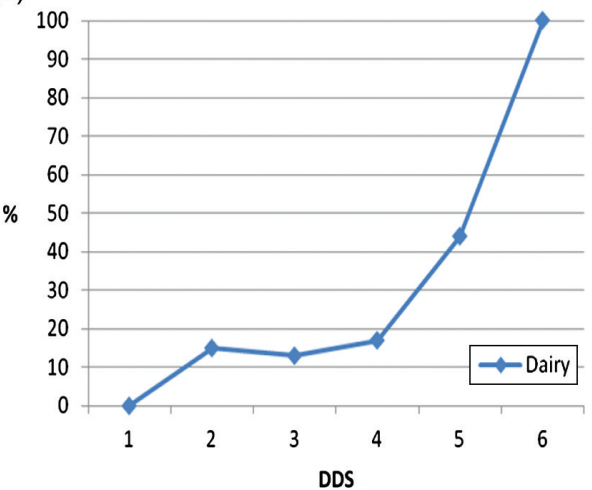

(e)

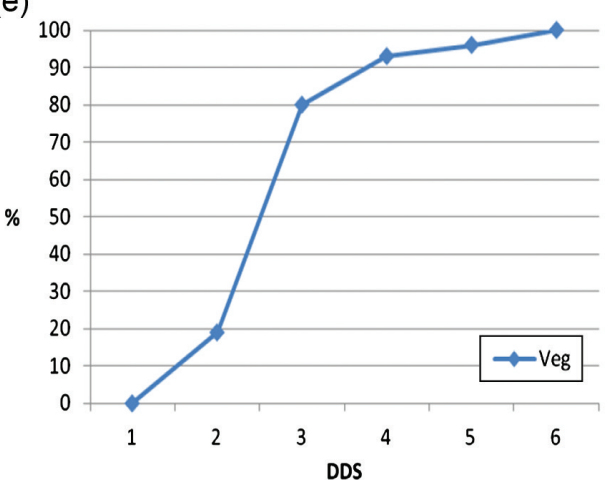

(b) 100

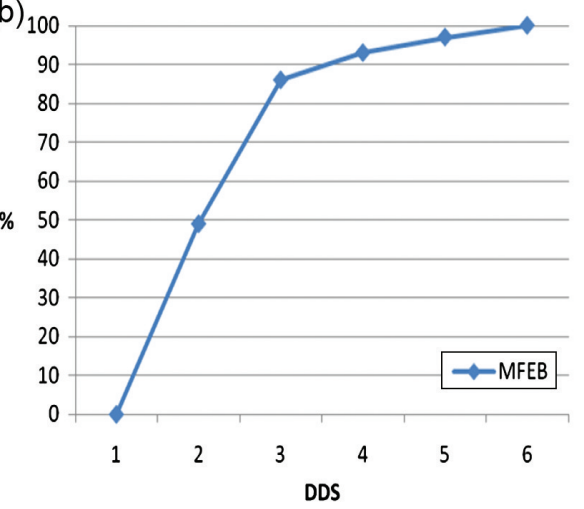

(d)

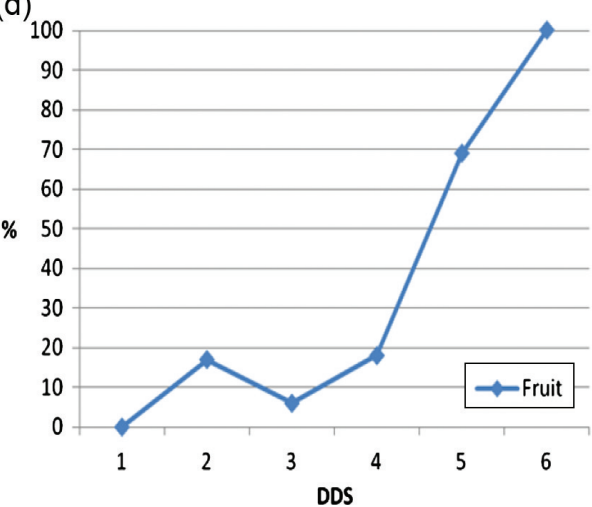

(f)

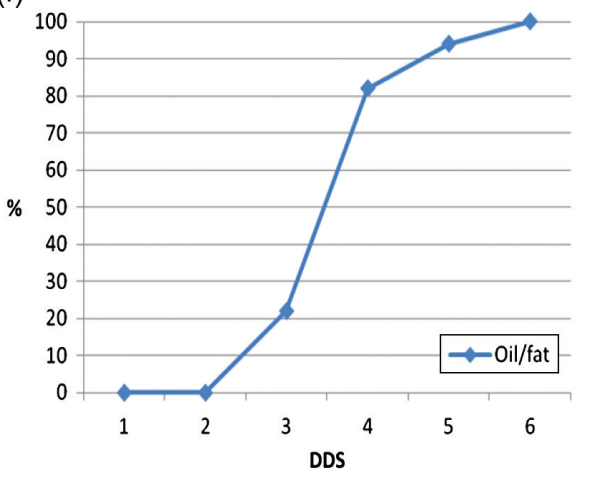

Supplementary Figure 1-1. Proportion of population which achieves a daily food group of one unit in accordance with the dietary diversity score (DDS) for mild cognitive impairment (1-2 errors). 
(a)

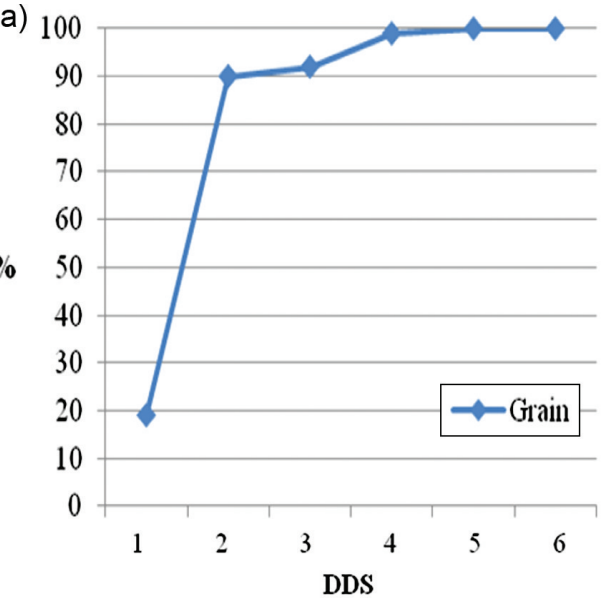

(c)

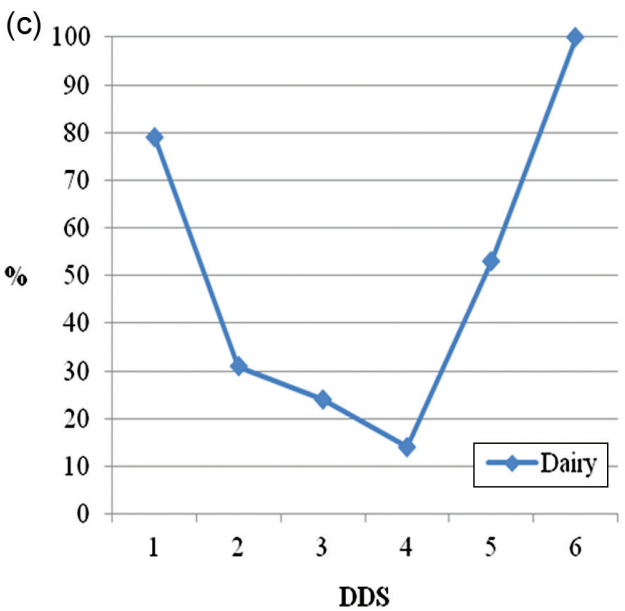

(e)

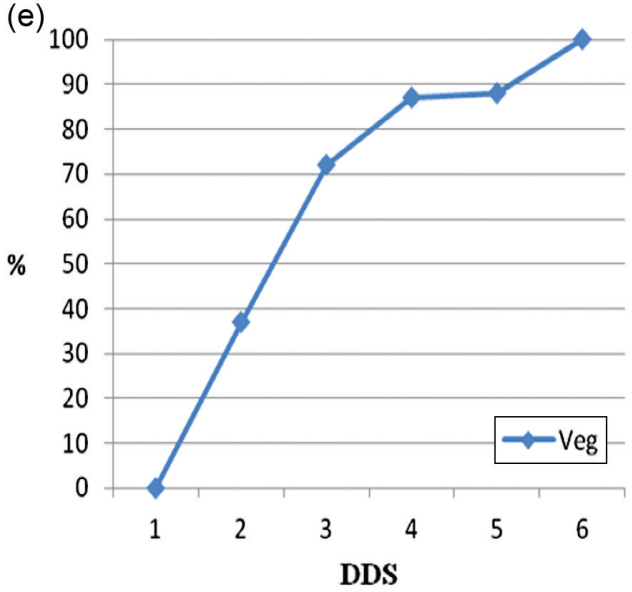

(b)

$\%$

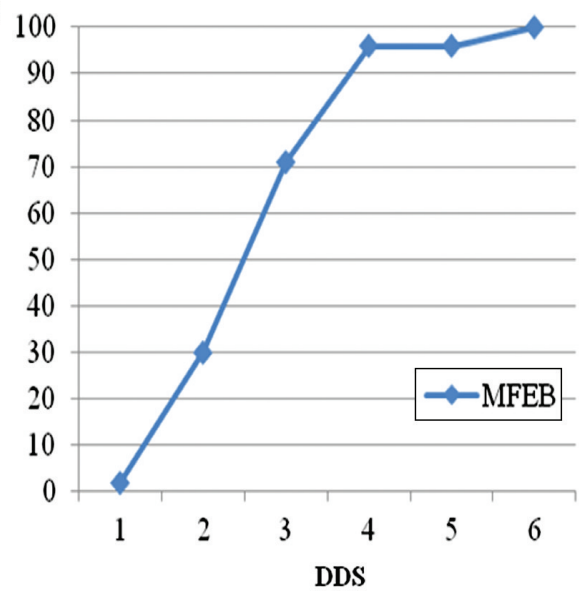

(d)

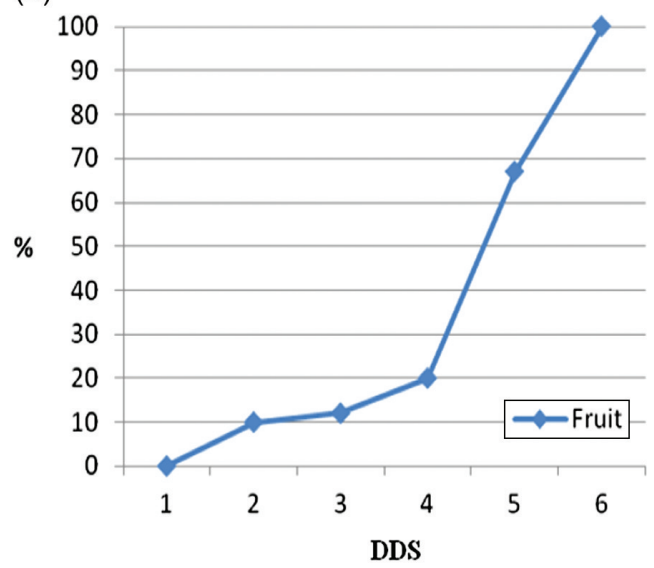

(f)

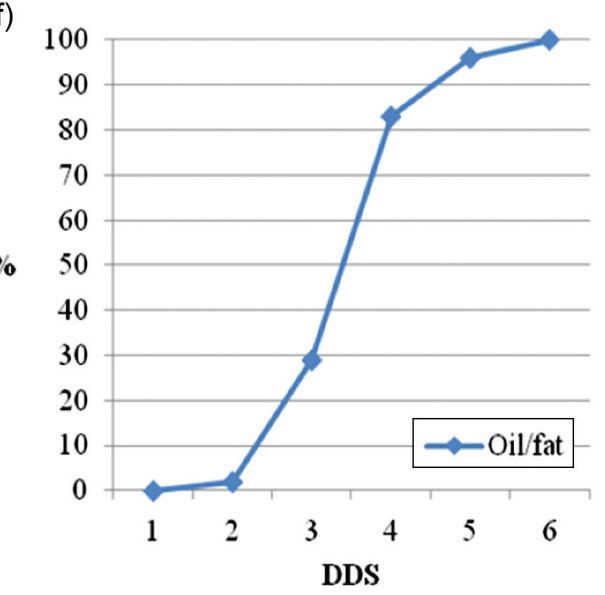

Supplementary Figure 1-2. Proportion of population which achieves a daily food group of one unit in accordance with the dietary diversity score (DDS) for moderate/severe cognitive impairment ( $\geq 3$ errors). 